\title{
Physicochemical Characterization of Broken Rice and Analysis of Its Volatile Compounds
}

\section{Charupa LOYDA ${ }^{1}$, Riantong SINGANUSONG ${ }^{1,2, *}$, Arporn JARANRATTANASRI ${ }^{1,2}$ and Worasit TOCHAMPA ${ }^{1,2}$}

\author{
${ }^{1}$ Department of Agro-Industry, Faculty of Agriculture, Natural Resources and Environment, \\ Naresuan University, Phitsanulok 65000, Thailand \\ ${ }^{2}$ Centre of Excellence in Fats and Oils, Faculty of Agriculture, Natural Resources and Environment, \\ Naresuan University, Phitsanulok 65000, Thailand
}

('Corresponding author's e-mail: riantongs@nu.ac.th)

Received: 12 November 2019, Revised: 16 April 2020, Accepted: 20 May 2020

\begin{abstract}
The term "broken rice" refers to fragments of rice grains broken during the milling process. Broken rice is generally classified into 3 sizes: large, medium, and small. Broken rice can be widely used for the pet food industry, livestock feeding, aquaculture, laundry starch, cosmetics, and textile manufacture. The purpose of this study was to determine certain properties of raw large broken rice (LBR) and small broken rice (SBR) of 4 commercially important varieties: Khao Dawk Mali105 (KDML105), Pathumtani1 (PTT1), Chainat1 (CN1), and Kor-khor6 (RD6). The properties analyzed were pasting properties, alkali spreading value, gel consistency, chemical composition, and amylose content. Volatile components of the LBR and SBR samples were also identified. Results revealed that each rice variety had different rheological characteristics. SBR of KDML105, PTT1, and CN1 had alkaline spreading value (ASV) in the range of $3-7$. The rice flour gel of the glutinous rice variety RD6 showed the highest flow distance in both LBR and SBR forms. CN1 had the highest amylose content in both LBR and SBR forms, while RD6 had the lowest. Among all the samples, the 6 most abundant volatile components detected were alcohols, aldehydes, furans, ketones, sulfur, and terpenes. The 3 volatile compounds with the highest odor active values (OAV) in both LBR and SBR forms were hexanal, heptanal, and 3-methylbutanal.
\end{abstract}

Keywords: Broken rice, Chainat1, Khao Dawk Mali105, Kor-Khor6, Pathumtani1, Volatile components

\section{Introduction}

Rice (Oryza sativa L.) is an important source of food for much of the world's population. Consumers pay attention to rice grain quality, displaying personal preferences for rice with a particular visual appearance, texture, flavor, and aroma [1]. Rice grains are composed of approximately $80-85 \%$ starch, $4-10 \%$ protein, $1 \%$ lipids and $10 \%$ moisture [2]. Starch, protein, and lipids can all affect cooking and eating quality [3]. Rice composition varies with the cultivar, growing and harvesting conditions, milling process, and storage conditions and duration. Milled rice carbohydrate contains amylose and amylopectin in different proportions, depending on the rice cultivar. Amylose content is a key indicator for predicting the behavior of rice during cooking and processing in that it influences the texture, water absorption ability, and hardness [3].

Chemical constituents are important to the aroma of cooked rice. Aromatic rice contains 2-acetyl-1pyrroline (2-AP) as the active aroma compound most contributing to its flavor [4]. Lipid oxidation products have also been identified which have a negative impact on palatability [5]. Cooked rice has odor-active compounds formed during the degradation of oleic, linoleic, and linolenic acids, the principal 
http://wjst.wu.ac.th

unsaturated fatty acids present [3]. Octanal, heptanal, nonanal, (E)-2-nonenal, decanal, and 2-heptanone are formed from oleic acid, whereas hexanal, pentanal, pentanol, $(E)$-2-octenal, $(E, E)$-2,4-decadienal and 2-pentylfuran are formed from linoleic acid [6].

The term "broken rice" refers to fragments of rice grains broken during the milling process. Broken rice is generally classified into 3 sizes: large, medium, and small [7]. Broken rice, which accounts for less than $11 \%$ of the rice yield, is produced inevitably due to the requirements of accuracy during rice processing. Broken rice has the same composition as unbroken rice but its taste is considered inferior; thus, it is used for low-quality products or animal feed [8]. Despite its low status, a kilogram of broken rice is generally only $8-10$ Baht less expensive than a kilogram of full-grain rice, depending on rice cultivar.

Currently, Thailand can produce large quantities of rice for the world market, and there are other international competitors as well, the result being periodic declines in the price of rice. Therefore, new ways of utilizing rice, particularly broken rice, and expanding the nutritional value of other foods by the addition of rice can help address rice surpluses. For example, both LBR and SBR can be processed into roasted rice powder for further use in the manufacture of traditional fermented fish and used as an ingredient in some Thai food menus. The purpose of this study was to determine certain properties and identify volatile components of LBR and SBR from 4 commercially important rice varieties that are relevant when choosing a variety for further roasting and using as an ingredient in foods.

\section{Materials and methods}

\section{Rice samples and samples preparation}

LBR and SBR samples of Khao Dawk Mali105 (KDML105), Pathumtani1 (PTT1), Chainat1 (CN1), and Kor-khor6 (RD6) cultivars were used in this study, for a total of 8 samples. These cultivars were selected to represent non-glutinous rice (KDML105, PTT1, and CN1), glutinous rice (RD6), and various levels of amylose content. In 2015, KDML105 and PTT1 were freshly harvested from Nakhon Sawan Province, Thailand, whereas CN1 and RD6 were freshly harvested from Phitsanulok Province. They were piled and kept at room temperature at the rice miller for $6,4,3$, and 3 months, respectively before milling. Five $\mathrm{kg}$ of each of the 8 samples were packed in polyethylene bags and stored at $-18^{\circ} \mathrm{C}$ until use for analysis. Before each analysis was carried out, the necessary amount of the relevant sample was removed from its $5.0 \mathrm{~kg}$ polyethylene bag. The bag was, then, immediately returned to the freezer and the test sample was allowed to warm up to room temperature. Before analyzing the sample for its physical, physicochemical, and chemical properties, any foreign materials were removed. A portion of the sample was ground to form the rice flour and passed through a 100-mesh sieve necessary for the determination of pasting properties, gel consistency, chemical composition, acid value, peroxide value, and amylose content. The broken rice was roughly ground to a smaller size for volatile compounds analysis.

\section{Chemicals}

All the volatile standards were analytical grade, including the following standards used for GC-MS identification and other analysis purposes: 3-methylbutanal, hexanal, heptanal, and 2-pentylfuran (SigmaAldrich, Poole, Dorset, UK). Potassium hydroxide, sodium hydroxide, acetic acid, ethanol, and methanol (HPLC grade) were purchased from RCI Labscan (Bangkok, Thailand). Sodium thiosulfate, thymol blue, and phenolphthalein were purchased from Loba Chemie Pvt. Ltd. (Mumbai, India). Iodine was Univar ${ }^{\circledR}$ analytical reagent grade and was purchased from Ajax Finechem Pty. Ltd. (Australia).

\section{Physical properties}

The color L*, $a^{*}, b^{*}$ of each variety's LBR and SBR were measured with a colorimeter (HUNTER LAB, DP 9000, U.S.A.). The pasting properties of the rice flour were measured using a Rapid Visco Analyser (RVA, Super 3, Newport Scientific Pty. Ltd., Australia). A set cycle of a series of precise temperatures and stirring velocities was used to measure the pasting viscosities of each rice flour sample. The parameters determined were pasting temperature, peak viscosity, trough viscosity, breakdown, final 
viscosity, setback, and consistency. This information was then used to find the corresponding cooking and processing characteristics of the rice.

\section{Alkali spreading value (ASV)}

ASV is a measurement describing the gelatinous character of rice, which enables one to estimate the gelatinization temperature (GT), applying the method of Chemutai et al. [9]. One hundred kernels were soaked for $23 \mathrm{~h}$ in $100 \mathrm{ml}$ of $1.7 \%$ potassium hydroxide. The kernels were then evaluated visually and assigned scores ranging from 1 to 7 as follows: $1-3=$ high GT, $4-5=$ intermediate GT, and $6-7=$ low GT. The scores of the 100 kernels were averaged for the final score.

\section{Gel consistency}

Gel consistency of rice was determined using the method of Chemutai et al. [9]. A rice flour sample of $0.1 \mathrm{~g}$ was weighed into each tube and $0.026 \mathrm{ml}$ of $95 \%$ ethanol containing $0.025 \%$ thymol blue was added and the combination was mixed with a vortex mixer at speed 6 and then $2 \mathrm{ml}$ of $0.2 \mathrm{~N} \mathrm{KOH}$ was added and vortexed again. Each tube was covered with a glass marble and the tubes were heated in a boiling water bath $\left(92^{\circ} \mathrm{C}\right)$ for $6 \mathrm{~min}$. Outside the water bath, the tubes stood at room temperature for 5 $\mathrm{min}$. Then, the tubes were cooled in an ice-water bath for $15 \mathrm{~min}$, and place flat on their side for $30 \mathrm{~min}$ on ruled graphing paper laid out on a laboratory table. Finally, the total length of each tube's blue-colored gel was measured in millimeters to index their cold paste viscosity into levels.

\section{Chemical composition}

Each rice's chemical composition, including its moisture, lipid, and protein content, was determined according to the official standard method of AOAC [10].

\section{Determination of acid value}

Determination of acid value followed the method of AOAC [10]. Rice flour samples of $5.0 \mathrm{~g}$ were dissolved in $50 \mathrm{~mL}$ of $95 \%$ ethanol in Erlenmeyer flasks. The solution was mixed by swirling each flask in the hand and then titrated against $0.1 \mathrm{~N}$ potassium hydroxide using $1 \mathrm{~mL}$ of $1 \%$ phenolphthalein solution as an indicator, swirling the flask again until a pink color appeared, and continuing to swirl for an additional $30 \mathrm{~s}$ after that. The volume of potassium hydroxide titrant used was read and the acid value was calculated using the following formula:

Acid value $(\mathrm{mg} \mathrm{KOH} / \mathrm{g})=(\mathrm{M} \times \mathrm{V}) \times(\mathrm{N} / \mathrm{W})$

Where $\mathrm{M}=$ molecular weight of potassium hydroxide $(56.11), \mathrm{V}=$ volume $(\mathrm{ml})$ of potassium hydroxide, $\mathrm{N}=$ normality of the potassium hydroxide solution, and $\mathrm{W}=$ weight of the rice flour sample (g)

\section{Determination of peroxide value}

Determination of peroxide value also followed the method of AOAC [10]. Rice flour samples of $5.0 \mathrm{~g}$ were weighed into Erlenmeyer flasks and dissolved with $30 \mathrm{ml}$ of an acetic acid-chloroform mixture $(3: 2)$. Saturated potassium iodide solution $(0.5 \mathrm{ml})$ was added and swirled in, and the mixture was allowed to stand for exactly $1 \mathrm{~min}$. Then the flask was swirled for exactly $1 \mathrm{~min}$, and $30 \mathrm{~mL}$ of water was added and swirled in. The mixture was titrated with $0.01 \mathrm{~N}$ sodium thiosulfate, adding the titrant slowly with continuous swirling, until a yellow color appeared. At that point, $5 \mathrm{ml}$ of starch TS was added, and the titration was continued with swirling until a blue color appeared. A blank determination was performed under the same conditions, but without the rice flour. The peroxide value was calculated according to the following formula: 
http://wjst.wu.ac.th

Peroxide value $(\mathrm{meq} / \mathrm{kg})=[1000(\mathrm{VT}-\mathrm{VB}) \times \mathrm{N}] / \mathrm{W}$

where $\mathrm{VT}=$ volume of $0.01 \mathrm{~N}$ sodium thiosulfate consumed in the actual test $(\mathrm{ml}), \mathrm{VB}=$ volume of 0.01 $\mathrm{N}$ sodium thiosulfate consumed in the blank test $(\mathrm{ml}), \mathrm{N}=$ exact normality of the sodium thiosulfate solution, and $\mathrm{W}=$ weight of the rice flour sample used in the test $(\mathrm{g})$.

\section{Apparent amylose content}

Amylose content was analyzed using a colorimetric method of Juliano et al. [11], which is based on the ability of amylose to bind to iodine. To solubilize a sample, rice flour was $1^{\text {st }}$ wet with ethanol and then digested with sodium hydroxide. An auto-analyzer was then used to adjust the sample's $\mathrm{pH}$ by adding acetic acid. Next, iodine was added and the color change was measured using a spectrophotometer. The sample's apparent amylose content was calculated by comparing its measured color to that of several standards analyzed using the same method. The amylose content predicts the firmness of the cooked rice.

\section{Volatile compounds}

Isolation of volatiles using Tenax-TA trap

LBR and SBR samples were ground and $3.0 \mathrm{~g}$ were weighed into a purge and trap sample tube. The tubes were injected with $3 \mu \mathrm{L}$ of 2-methyl-3-heptanone as an internal standard. Each purge and trap tube were placed in a concentrator, where ultra-purified helium was used as the purging gas at $40 \mathrm{ml} / \mathrm{min}$ at $60{ }^{\circ} \mathrm{C}$ for $15 \mathrm{~min}$. Headspace volatiles emanating from the rice samples were collected on a stainlesssteel Tenax trap with $150 \mathrm{mg}$ 60/80 mesh Tenax-TA. The Tenax trap was then desorbed by heating to $225^{\circ} \mathrm{C}$ for $1 \mathrm{~min}$ with $300 \mathrm{ml} / \mathrm{min}$ of ultra-purified helium. Finally, the volatiles were injected into a gas chromatography-mass spectrometer (GC-MS).

\section{GC-MS analysis}

GC-MS analysis applied the method adapted from Jaranrattanasri et al. [12]. GC-MS was performed using a 2010 plus GC/mass selective detector (MSD) (Shimadzu). The volatiles were injected into a DB5MS (30 m length, $0.25 \mathrm{~mm}$ i.d., $0.25 \mu \mathrm{m}$ film thickness) fused silica capillary column. The GC oven temperature was programmed for $40{ }^{\circ} \mathrm{C}$ for $5 \mathrm{~min}$, then raised at $2{ }^{\circ} \mathrm{C} / \mathrm{min}$ to $100{ }^{\circ} \mathrm{C}$, and finally raised at $5{ }^{\circ} \mathrm{C} / \mathrm{min}$ to $225^{\circ} \mathrm{C}$ and held for $10 \mathrm{~min}$. Helium was used as the carrier gas at a constant flow of $2 \mathrm{ml} / \mathrm{min}$. The mass spectrometer was operated in electron impact mode with an electron energy of $70 \mathrm{eV}$. The mass spectrometer was scanned from $\mathrm{m} / \mathrm{z} 35$ to $\mathrm{m} / \mathrm{z} 350$ at 1.9 scans/s. The MSD interface temperature was $250^{\circ} \mathrm{C}$.

\section{Compound identification}

Compounds were positively identified by comparing their mass spectra and retention indices (RI) on the DB5-MS column to those of reference compounds analyzed under identical conditions. RI values were determined by analyzing a series of n-alkanes (C6-C28 DB5-MS).

\section{Compound quantification}

The concentration of each aroma component was calculated using the internal standard methodology of GC-MS with a DB5-MS column as described above. Prior to GC-MS analysis of the rice flour samples, reference standards (at 3 different levels), as well as internal standards, were diluted in methanol. The values reported in this study were considered relative concentrations.

\section{Statistical analysis}

All measurements were performed identically 3 times and experimental results are expressed as means. The data were analyzed by analysis of variance (ANOVA) and the means were separated by Duncan's multiple range tests at a $5 \%$ significance level. 


\section{Results and discussion}

\section{Physical properties}

Color

All the $\mathrm{L}^{*}, \mathrm{a}^{*}$, and $\mathrm{b}^{*}$ values of the SBR and LBR of the 4-rice cultivars are displayed in Table 1. The $\mathrm{L}^{*}, \mathrm{a}^{*}$ and $\mathrm{b}^{*}$ of the SBR of all 4 rice cultivars were significantly higher $(p \leq 0.05)$ than those of their corresponding LBR. The SBR with the highest L* (72.75) $(p \leq 0.05)$ was that of RD6, since RD6 is glutinous rice with an opaque white grain, while KDML105, PTT1, and CN1 are non-glutinous kinds of rice that have somewhat translucent grains [13]. RD6's high L*value gives this variety's grain the brightest appearance among the 4 rice cultivars. The $\mathrm{a}^{*}$ values of the SBRs of KDML105 and PTT1 were 0.32 and 0.15 , respectively and these were the highest $\mathrm{a}^{*}$ values $(p \leq 0.05)$ among the 4 cultivars, while the SBR of CN1 had the highest $\mathrm{b}^{*}(p \leq 0.05)$. The L* of RD6's LBR (68.85) $(p \leq 0.05)$ was the highest among all the LBRs. The LBRs of KDML105, PTT1, and CN1 were not significantly different $(p>0.05)$ in their $a^{*}$ values. The $b^{*}$ values of KDML105 and PT1's LBRs were 10.04 and 9.97, respectively. Although these 2 values are not significantly different from each other $(p>0.05)$, they are the highest $b^{*}$ values among the LBRs. These differences can be attributed to variations in the rice cultivars themselves, their planting conditions, harvesting conditions, milling conditions, and storage conditions.

Table 1 Color characteristics of broken rice.

\begin{tabular}{ccccc}
\hline \multirow{2}{*}{$\begin{array}{c}\text { Broken rice } \\
\text { type }\end{array}$} & \multicolumn{5}{c}{ Rice varieties } \\
\cline { 2 - 5 } & KDML105 & PTT1 & CN1 & RD6 \\
\cline { 2 - 5 } LBR & $55.21 \pm 1.73^{\mathrm{cB}}$ & $56.46 \pm 0.48^{\mathrm{cB}}$ & $60.37 \pm 0.58^{\mathrm{bB}}$ & $68.85 \pm 1.73^{\mathrm{aB}}$ \\
SBR & $62.22 \pm 1.57^{\mathrm{cA}}$ & $61.51 \pm 0.33^{\mathrm{cA}}$ & $64.21 \pm 0.84^{\mathrm{bA}}$ & $72.75 \pm 0.36^{\mathrm{aA}}$ \\
\hline & & & $\mathbf{a}^{*}$ & \\
& & & & \\
LBR & $-0.50 \pm 0.02^{\mathrm{abB}}$ & $-0.24 \pm 0.27^{\mathrm{aB}}$ & $-0.45 \pm 0.10^{\mathrm{abB}}$ & $-0.72 \pm 0.16^{\mathrm{bA}}$ \\
SBR & $0.32 \pm 0.26^{\mathrm{aA}}$ & $0.15 \pm 0.10^{\mathrm{abA}}$ & $-0.11 \pm 0.10^{\mathrm{bA}}$ & $-0.69 \pm 0.03^{\mathrm{cA}}$ \\
\hline & & & & \\
\cline { 2 - 5 } LBR & $10.04 \pm 1.04^{\mathrm{aB}}$ & $9.97 \pm 0.49^{\mathrm{abB}}$ & $8.65 \pm 0.74^{\mathrm{bB}}$ & $8.48 \pm 0.37^{\mathrm{bB}}$ \\
SBR & $13.09 \pm 0.16^{\mathrm{bA}}$ & $12.35 \pm 0.17^{\mathrm{bA}}$ & $14.42 \pm 0.38^{\mathrm{aA}}$ & $9.66 \pm 0.15^{\mathrm{cA}}$ \\
\hline
\end{tabular}

All values are means of triplicates \pm standard deviation. Means with different letters $(\mathrm{a}-\mathrm{c})$ within the same row were significantly different $(p \leq 0.05)$. Means with different letters (A - B) within the same column were significantly different $(p \leq 0.05)$.

\section{Pasting properties}

Pasting properties were examined to estimate the cooking and processing characteristics of the rice. The pasting behaviors of starch gels have been reported to be affected by amylopectin, amylose, and lipids. Amylopectin mainly responsible for the swelling of starch granules and pasting, while amylose and lipids inhibit the swelling by maintaining the integrity of the swollen starch granules. The waxy or low amylose rice starch is mainly composed of amylopectin with an absence of amylose-lipid complexes; thus, starch granule can swell easily, providing lower pasting temperature and higher peak viscosity. During cooling of the starch paste, a more solubilized starch particularly amylose released can reassociate rapidly. 
The amylose junction zones are formed and viscosity increases again (final viscosity) which reflects gel network formation involving amylose [14]. The pasting properties of LBR and SBR of KDML105, PTT1, CN1, and RD6 as determined using an RVA are shown in Table 2. The pasting temperatures of the different SBR flours were significantly higher $(p \leq 0.05)$ than those of their corresponding LBR flours, indicating that these SBRs had higher gelatinization temperatures than their corresponding LBRs. The peak, trough, and final viscosities of the 4 LBR flours were almost all significantly higher $(p \leq 0.05)$ than their SBR flours, except for the final viscosity of PTT1, which was significantly lower $(p \leq 0.05)$ than its SBR flour. The final viscosity parameter indicates the quality of rice flour, and this parameter affects the characteristics of the flour itself and products made with that flour [15]. Thus, after heating and cooling, LBRs produce a harder gel than SBRs. Breakdown measured the susceptibility of starch paste to thermal and mechanical shear, while setback viscosity presented the tendency of starch paste to retrograde [14]. Breakdown values of the LBR flours were significantly higher $(p \leq 0.05)$ than those of the SBR flours, indicating that the ability of LBR to resist high temperature and agitation is lower than that of SBR. The setback, evaluated by the viscosity of the end of the RVA program minus trough viscosity, reflected the change in viscosity between the hot paste and the gel formed after cooling [16]. The setback values of the SBR flours were significantly higher $(p \leq 0.05)$ than those of the LBR flours, so SBRs have higher retrogradation than LBRs and SBRs tend to produce a harder gel.

Table 2 Pasting properties of broken rice, as measured by RVA.

\begin{tabular}{|c|c|c|c|c|}
\hline \multirow{2}{*}{$\begin{array}{c}\text { Broken rice } \\
\text { type }\end{array}$} & \multicolumn{4}{|c|}{ Rice varieties } \\
\hline & KDML105 & PTT1 & CN1 & RD6 \\
\hline & \multicolumn{4}{|c|}{ Pasting temperature $\left({ }^{\circ} \mathrm{C}\right)$} \\
\hline LBR & $84.70 \pm 0.03^{\mathrm{aB}}$ & $79.43 \pm 0.22^{\mathrm{cB}}$ & $81.48 \pm 0.01^{\mathrm{bB}}$ & $71.25 \pm 0.00^{\mathrm{dA}}$ \\
\hline \multirow[t]{2}{*}{ SBR } & $87.08 \pm 0.04^{\mathrm{cA}}$ & $87.85 \pm 0.03^{\mathrm{bA}}$ & $88.35 \pm 0.30^{\mathrm{aA}}$ & $70.55 \pm 0.03^{\mathrm{dB}}$ \\
\hline & \multicolumn{4}{|l|}{ Peak viscosity (cP) } \\
\hline LBR & $3,111.50 \pm 31.46^{\mathrm{cA}}$ & $3,417.50 \pm 19.34^{\mathrm{aA}}$ & $3,280.50 \pm 11.84^{\mathrm{bA}}$ & $3,165.00 \pm 18.48^{\mathrm{cA}}$ \\
\hline \multirow[t]{2}{*}{ SBR } & $2,404.00 \pm 12.70^{\mathrm{bB}}$ & $2,355.50 \pm 31.47^{\mathrm{bcB}}$ & $2,304.50 \pm 4.33^{\mathrm{cB}}$ & $2,695.00 \pm 22.52^{\mathrm{aB}}$ \\
\hline & \multicolumn{4}{|c|}{ Trough viscosity (cP) } \\
\hline LBR & $1,956.00 \pm 40.99^{\mathrm{bA}}$ & $1,810.00 \pm 16.17^{\mathrm{cA}}$ & $2,092.00 \pm 19.63^{\mathrm{aA}}$ & $1,793.50 \pm 9.53^{\mathrm{cA}}$ \\
\hline \multirow[t]{2}{*}{ SBR } & $1,450.00 \pm 16.17^{\mathrm{cB}}$ & $1,532.50 \pm 0.87^{\mathrm{bB}}$ & $1,779.50 \pm 1.44^{\mathrm{aB}}$ & $1,461.50 \pm 4.33^{\mathrm{cB}}$ \\
\hline & \multicolumn{4}{|l|}{ Breakdown (cP) } \\
\hline LBR & $1,155.50 \pm 72.46^{\mathrm{cA}}$ & $1,607.50 \pm 3.18^{\mathrm{aA}}$ & $1,188.50 \pm 31.47^{\mathrm{cA}}$ & $1,371.50 \pm 28.00^{\mathrm{bA}}$ \\
\hline \multirow[t]{2}{*}{ SBR } & $954.00 \pm 3.46^{\mathrm{bB}}$ & $823.00 \pm 32.33^{\mathrm{cB}}$ & $525.00 \pm 5.77^{\mathrm{dB}}$ & $1,233.50 \pm 18.19^{\mathrm{aA}}$ \\
\hline & \multicolumn{4}{|l|}{ Final viscosity (cP) } \\
\hline LBR & $3,841.00 \pm 22.52^{\mathrm{bA}}$ & $3,347.00 \pm 25.40^{\mathrm{cB}}$ & $6,129.50 \pm 32.62^{\mathrm{aA}}$ & $2,462.00 \pm 0.58^{\mathrm{dA}}$ \\
\hline \multirow[t]{2}{*}{ SBR } & $3,325.50 \pm 29.73^{\mathrm{cB}}$ & $3,591.50 \pm 26.27^{\mathrm{bA}}$ & $4,638.00 \pm 87.76^{\mathrm{aB}}$ & $1,999.00 \pm 5.20^{\mathrm{dB}}$ \\
\hline & \multicolumn{4}{|c|}{ Setback from peak (cP) } \\
\hline LBR & $729.50 \pm 53.98^{\mathrm{bB}}$ & $-70.50 \pm 6.06^{\mathrm{cB}}$ & $2,849.00 \pm 20.78^{\mathrm{aB}}$ & $-703.00 \pm 17.90^{\mathrm{dA}}$ \\
\hline SBR & $921.50 \pm 17.03^{\mathrm{cA}}$ & $1,236.00 \pm 5.20^{\mathrm{bA}}$ & $2,333.50 \pm 83.42^{\mathrm{aA}}$ & $-696.00 \pm 27.71^{\mathrm{dA}}$ \\
\hline
\end{tabular}

All values are means of triplicates \pm standard deviation. Means with different letters $(a-d)$ within the same row were significantly different $(p \leq 0.05)$. Means with different letters $(\mathrm{A}-\mathrm{B})$ within the same column were significantly different $(p \leq 0.05)$. 
Regarding the specific cultivars tested, CN1 had the highest pasting temperature, final viscosity, and setback, and thus produced the hardest gel among the tested cultivars. After CN1, the next hardest gels were produced by KDML105 and PTT1. RD6 had the lowest pasting temperature, final viscosity and setback, and so produced the softest gel. However, RD6 had the highest breakdown, indicating a low ability to resist high temperature and agitation. Rice with high peak viscosity, large breakdown value, small final viscosity, and small and negative setback value is considered to have good cooking and eating quality [17], which is RD6 according to these qualifications.

These results show that the pasting properties of rice flours, which describe the texture of cooked rice, vary from one rice cultivar to another. Each rice cultivar varied in amylose content, pasting temperature, viscosity, break down, final viscosity, and setback viscosity [18].

\section{Physicochemical properties}

\section{Alkali spreading value}

ASV is used as an indirect method for the estimation of the cooking time of the rice grain. ASV in turn shows a strong inverse relation to gelatinization temperature which is frequently used as a mean for placing varieties into low, intermediate, and high cooking temperature classes [19]. It is affected by the amylose content [20]. The ASVs of both LBRs and SBRs of KDML105, PTT1, and RD6 were not significantly different $(p>0.05)$. The ASVs were found in the range of $6-7$ (Table 3), indicating a low GT and a short cooking time, while the ASV of CN1 was found in the range of 4 - 5 (Table 3), indicating a medium GT and a longer cooking time [9].

Table 3 Alkali spreading value and gel consistency of broken rice.

\begin{tabular}{|c|c|c|c|c|}
\hline \multirow{2}{*}{ Broken rice type } & \multicolumn{4}{|c|}{ Rice varieties } \\
\hline & KDML105 & PTT1 & CN1 & RD6 \\
\hline & \multicolumn{4}{|c|}{ Alkali spreading value (degree) } \\
\hline LBR & $6.62 \pm 0.08^{\mathrm{aA}}$ & $6.57 \pm 0.08^{\mathrm{aA}}$ & $4.87 \pm 0.10^{\mathrm{bB}}$ & $6.60 \pm 0.05^{\mathrm{aA}}$ \\
\hline \multirow[t]{2}{*}{ SBR } & $6.17 \pm 0.13^{\mathrm{aB}}$ & $6.25 \pm 0.33^{\mathrm{aB}}$ & $4.96 \pm 0.15^{\mathrm{bA}}$ & $6.52 \pm 0.03^{\mathrm{aB}}$ \\
\hline & Gel consistency & & & \\
\hline LBR & $61.33 \pm 1.53^{\mathrm{bB}}$ & $61.00 \pm 1.00^{\mathrm{cB}}$ & $18.67 \pm 1.15^{\mathrm{dB}}$ & $99.67 \pm 1.53^{\mathrm{aB}}$ \\
\hline SBR & $69.00 \pm 1.00^{\mathrm{bA}}$ & $65.00 \pm 1.00^{\mathrm{cA}}$ & $26.00 \pm 1.73^{\mathrm{dA}}$ & $103.67 \pm 1.31^{\mathrm{aA}}$ \\
\hline
\end{tabular}

All values are means of triplicates \pm standard deviation. Means with different lowercase letters $(a-d)$ within the same row were significantly different $(p \leq 0.05)$. Means with different uppercase letters $(\mathrm{A}-\mathrm{B})$ within the same column were significantly different $(p \leq 0.05)$. NS $=$ not significant.

\section{Gel consistency}

The gel consistency test is normally used to predict rice quality by measuring the distance that the cooked flour/ethanol mixture flows on the flat surface. The method classifies rice into 3 levels of gel consistency: 1) hard consistency kinds of rice have a flow less than $40 \mathrm{~mm}, 2$ ) medium consistency kinds of rice have a flow in the range $41-60 \mathrm{~mm}$, and 3) soft consistency kinds of rice have a flow greater than $60 \mathrm{~mm}[21]$.

The gel consistency of all the broken rice varieties tested is shown in Table 3. The SBRs of all 4 varieties had a flow distance greater than their LBRs, which makes sense because, as will be shown later in this study, the amylose content of SBR is lower than that of LBR. Among the 4 cultivars, the flow distances of both the LBR and the SBR of RD6 were the highest $(99.67$ and $103.67 \mathrm{~mm}$, respectively) ( $p$ $\leq 0.05)$, since RD6 is glutinous rice with a low amylose content and is classified as soft consistency rice. 
http://wjst.wu.ac.th

On the other hand, the flow distances of the LBRs and SBRs of KDML105 and PTT1 were all greater than $60 \mathrm{~mm}$, so these are medium consistency kinds of rice. CN1 LBR and SBR have a high amylose content and thus the lowest flow distances (18.67 and $26.00 \mathrm{~mm}$, respectively) ( $p \leq 0.05$ ), so CN1 is a hard consistency kind of rice. In general, there is an inverse relationship between gel consistency and amylose content [22], although 2 kinds of rice with the same amylose content may have a different gel consistency.

\section{Chemical composition and properties \\ Chemical composition}

The chemical composition and chemical properties of the LBRs and SBRs of KDML105, PTT1, $\mathrm{CN1}$, and RD6 are shown in Table 4. The moisture content of all the samples ranged from 10.71 to $12.12 \%$, which conforms to the standard value for Thai rice (below $14 \%$ ). Moisture content has a marked influence on all aspects of rice quality. All 4 varieties' SBRs had protein content significantly higher $(p \leq 0.05)$ than their LBRs, except for KDML105 in which the protein content levels were not significantly different $(p>0.05)$. Both the LBR and SBR of RD6 had the lowest protein content compared to other cultivars. The reason is probably that RD6 is glutinous rice and glutinous rice generally has lower protein content than non-glutinous rice [23]. All broken rice in this study had a protein content of $7.04-8.70 \%$, which is similar to the results reported by other researchers. The SBRs of all the varieties had significantly higher $(p \leq 0.05)$ lipid content than their corresponding LBRs. This is probably because SBR contains more rice germ than LBR and rice germ has a high lipid content. The LBR and SBR of RD6 were the lowest in lipid content ( 0.06 and $1.88 \%$, respectively) $(p \leq 0.05)$.

Table 4 Chemical composition and chemical properties of broken rice.

\begin{tabular}{|c|c|c|c|c|}
\hline \multirow{2}{*}{$\begin{array}{c}\text { Broken rice } \\
\text { type }\end{array}$} & \multicolumn{4}{|c|}{ Rice varieties } \\
\hline & KDML105 & PTT1 & CN1 & RD6 \\
\hline & Moisture (\% dry basis) & & & \\
\hline LBR & $11.31 \pm 0.05^{\mathrm{bA}}$ & $11.34 \pm 0.44^{\mathrm{bA}}$ & $10.71 \pm 0.08^{\mathrm{cB}}$ & $11.89 \pm 0.05^{\mathrm{aA}}$ \\
\hline \multirow[t]{2}{*}{ SBR } & $10.90 \pm 0.03^{\mathrm{cB}}$ & $11.06 \pm 0.06^{\mathrm{bcA}}$ & $11.21 \pm 0.07^{\mathrm{bA}}$ & $12.12 \pm 0.02^{\mathrm{aA}}$ \\
\hline & Protein (\% dry basis) & & & \\
\hline LBR & $8.33 \pm 0.17^{\mathrm{aA}}$ & $8.02 \pm 0.10^{\mathrm{bB}}$ & $8.08 \pm 0.04^{\mathrm{abB}}$ & $7.04 \pm 0.42^{\mathrm{cB}}$ \\
\hline \multirow[t]{2}{*}{ SBR } & $8.58 \pm 0.06^{\mathrm{abA}}$ & $8.68 \pm 0.06^{\mathrm{aA}}$ & $8.70 \pm 0.05^{\mathrm{aA}}$ & $7.58 \pm 0.05^{\mathrm{bA}}$ \\
\hline & Lipid (\% dry basis) & & & \\
\hline LBR & $1.43 \pm 0.27^{\mathrm{abB}}$ & $1.26 \pm 0.03^{\mathrm{bB}}$ & $1.51 \pm 0.03^{\mathrm{aB}}$ & $0.60 \pm 0.02^{\mathrm{cB}}$ \\
\hline \multirow[t]{2}{*}{ SBR } & $2.25 \pm 0.04^{\mathrm{bA}}$ & $2.32 \pm 0.06^{\mathrm{bA}}$ & $3.04 \pm 0.03^{\mathrm{aA}}$ & $1.88 \pm 0.08^{\mathrm{cA}}$ \\
\hline & Amylose (\%) & & & \\
\hline LBR & $21.14 \pm 0.00^{\mathrm{cA}}$ & $22.24 \pm 0.09^{\mathrm{bA}}$ & $28.91 \pm 0.08^{\mathrm{aA}}$ & $4.81 \pm 0.09^{\mathrm{dA}}$ \\
\hline \multirow[t]{2}{*}{ SBR } & $20.19 \pm 0.09^{\mathrm{cB}}$ & $21.34 \pm 0.08^{\mathrm{bB}}$ & $27.24 \pm 0.09^{\mathrm{aB}}$ & $3.95 \pm 0.08^{\mathrm{dB}}$ \\
\hline & Acid value (mg KOH/g) & & & \\
\hline LBR & $0.79 \pm 0.21^{\mathrm{B}}$ & $0.65 \pm 0.08^{\mathrm{B}}$ & $0.75 \pm 0.21^{\mathrm{B}}$ & $0.84 \pm 0.00^{\mathrm{A}}$ \\
\hline \multirow[t]{2}{*}{ SBR } & $1.30 \pm 0.16^{\mathrm{aA}}$ & $1.49 \pm 0.08^{\mathrm{aA}}$ & $1.31 \pm 0.01^{\mathrm{aA}}$ & $0.75 \pm 0.16^{\mathrm{bA}}$ \\
\hline & Peroxide value (meq/ kg) & & & \\
\hline LBR & ND & ND & ND & ND \\
\hline SBR & ND & ND & ND & ND \\
\hline
\end{tabular}

All values are means of triplicates \pm standard deviation. Means with different lowercase letters $(a-d)$ within the same row were significantly different $(p \leq 0.05)$. Means with different uppercase letters $(\mathrm{A}-\mathrm{B})$ within the same column were significantly different $(p \leq 0.05)$. ND $=$ not detected. 


\section{Acid value}

A rice's acid value is a measure of the amount of total fatty acids in that rice. High fatty acid content is associated with spoilage because during storage fatty acids can become rancid as they are liberated by hydrolysis from glycerides due to the effects of moisture, high temperature, and/or the lipolytic enzyme lipase [24]. Rice with a high fatty acid content is more vulnerable to turning rancid during storage. The products of fatty acid decomposition are free fatty acids, peroxide, low molecular weight aldehydes, and low molecular weight ketones. These substances result in an unpleasant odor and lower quality rice [25].

The SBR acid values of all 4 tested rice varieties were significantly higher $(p \leq 0.05)$ than those of the corresponding LBR (Table 4) since SBR contains more rice germ and rice bran than LBR. Rice bran is quite vulnerable to rancidity during storage due to its large amount of unsaturated lipids as well as the presence of hydrolytic and oxidative enzymes [26]. The acid value is directly correlated with the lipid content. In addition, the 4 tested LBRs did not have significantly different $(p>0.05)$ acid values. The SBR acid values of KDML105, PTT1 and CN1 were 1.30, 1.49, and $1.31 \mathrm{mg} \mathrm{KOH} / \mathrm{g}$, respectively. These 3 values are not significantly different $(p>0.05)$ from each other; however, all of them are significantly higher $(p \leq 0.05)$ than the acid value of RD6 SBR.

\section{Peroxide value}

Peroxides are primary oxidation products. Peroxides are quite unstable and decompose into a range of secondary products including aldehydes, alcohols, and ketones, all 3 of which produce a typical rancid oil odor [27]. In this study no peroxide was detected in any of the samples (Table 4), indicating that all of the samples were of good quality with no rancidity. The peroxide value and acid value are important indicators of food quality. The lower the peroxide and acid values, the better the quality of the fats and their state of preservation [28].

\section{Amylose content}

Amylose content strongly influences the cooking and eating characteristics of rice. Rice with a high amylose content $(25-33 \%)$ tends to cook up relatively firm, whereas rice with an intermediate amylose content $(20-25 \%)$ tends to be relatively soft. Rice with a low amylose content $(<20 \%)$ is generally even softer and sticky [29]. This is why rice with an amylose content of $0-5 \%$ is often referred to as sticky rice. The results in Table 4 show that the amylose content of LBR of all varieties was significantly higher $(p \leq 0.05)$ than that of the corresponding SBR. This is because SBR fragments are smaller than LBR's and so contain more rice germ, which has a high protein and lipid content [30]. All the SBRs had lower starch content than their corresponding LBR. Among the cultivars, CN1 had the highest amylose content and is therefore classified as firm rice. KDML105 and PTT1 had intermediate amylose content, and so are classified as soft rice. The amylose content of RD6 was the lowest, yielding even softer and sticky rice.

\section{Volatile compounds}

Among all the samples, the 6 most abundant volatile components detected were alcohols, aldehydes, furans, ketones, sulfur, and terpenes, as characterized by GC-MS (Table 5). Although, KDML105 and PTT1 are aromatic rice but 2-AP was not found in this study. This might be due to the instability of 2-AP. Loss of 2-AP in stored foods could be due to complexation, decomposition, diffusion to the environment, and generation of other compounds [31]. Widjaja et al. [32] investigated the effect of storage on 2-AP levels in paddy (rice with husk and rice bran), brown (rice without husk but with rice bran), and white (rice without husk and rice bran) rice samples that stored under 2 conditions: Atmospheric pressure and reduced pressure, at $84 \% \mathrm{RH}$ and $30^{\circ} \mathrm{C}$. After 3 months' storage, the 2-AP level was reduced by $40-50$ $\%$ in all cases, which supports the results of this research. Furthermore, the 2-AP could be lost during a milling process, particularly for the broken rice where the endosperm of the rice grain was exposed to an environmental condition during milling. An OAV can be assigned for any given volatile compound and it is obtained by dividing the concentration of the individual compound by its odor threshold, which is the lowest detectable concentration. Compounds with a high OAV $(\geq 1)$ contribute more to the aroma and are 
http://wjst.wu.ac.th

important in causing flavor differences among foods [33]. OAV testing revealed that 3 main odor active compounds were producing odor in the rice variety samples: Hexanal, heptanal, 3-methylbutanal, as seen in Table 6. Hexanal was producing odor (with high OAVs) in all 8 samples, while heptanal and 3-methylbutanal were producing odor in 5 samples each.

Table 5 Volatile content in broken rice.

\begin{tabular}{|c|c|c|c|c|c|c|c|c|c|}
\hline \multirow{3}{*}{ No. } & \multirow{3}{*}{ Compound $^{a}$} & \multicolumn{8}{|c|}{ Concentration $(\mathbf{n g} / \mathbf{g})^{c}$} \\
\hline & & \multicolumn{4}{|c|}{ LBR } & \multicolumn{4}{|c|}{ SBR } \\
\hline & & KDML105 & PTT1 & CN1 & RD6 & KDML105 & PTT1 & CN1 & RD6 \\
\hline 1 & 2-methyl-1-propanol & ND & ND & ND & ND & ND & 8.66 & ND & ND \\
\hline 2 & 3-methylbutanal ${ }^{b}$ & ND & 6.07 & 11.49 & ND & 14.14 & 7.46 & 17.52 & ND \\
\hline 3 & Dimethyl disulfide & 11.54 & 8.78 & 10.64 & 1.16 & 10.62 & 6.92 & ND & 3.17 \\
\hline 4 & n-Hexanal ${ }^{b}$ & 82.04 & 70.98 & 140.72 & 347.85 & 405.94 & 188.71 & 176.20 & 546.97 \\
\hline 5 & 1-Hexanol & ND & ND & 0.08 & ND & ND & ND & 0.13 & ND \\
\hline 6 & 2-Heptanone & 2.52 & 1.65 & 2.78 & 6.06 & 2.62 & 2.47 & ND & 13.95 \\
\hline 7 & $\mathrm{n}$-Heptanal ${ }^{b}$ & 2.73 & 2.92 & 7.01 & 3.37 & 4.86 & 4.77 & 2.71 & 4.92 \\
\hline 8 & -(-)B-Pinene & 1.12 & ND & ND & ND & ND & ND & ND & ND \\
\hline 9 & 2-Pentylfuran ${ }^{b}$ & 2.49 & 2.68 & 3.89 & 8.01 & 4.68 & 2.49 & 3.14 & 15.75 \\
\hline 10 & n-Octanal & 0.20 & ND & 0.64 & ND & ND & ND & 0.45 & ND \\
\hline 11 & S-(-)-(Limonene) & 6.64 & 0.81 & 1.12 & 0.87 & 0.87 & 0.64 & 1.53 & 1.64 \\
\hline
\end{tabular}

${ }^{a}$ All compounds were confirmed by linear retention index, mass spectra comparison with NIST and Wiley data bases.

${ }^{b}$ All compounds were confirmed by linear retention index, mass spectra comparison with NIST and Wiley data bases, and comparison with authentic standards.

${ }^{c}$ Mean $(\mathrm{n}=3)$

$\mathrm{ND}=$ not detected

Hexanal and heptanal are derived from lipids. Hexanal is a secondary oxidation product of linoleic acid that contributes to consumer rejection of rice due to its rancid odor and/or off flavor [34,35]. In this study, hexanal content was significantly higher $(p \leq 0.05)$ in the SBR of all varieties than in the corresponding LBR. Hexanal content was highest in the SBR of RD6 (546.97ng/ g), followed by the SBR of KDML105 (405.94 ng/g). The results for hexanal OAV followed the same pattern seen for hexanal content. Hexanal OAV was significantly higher $(p \leq 0.05)$ in the SBR of all 8 varieties compared to the corresponding LBR. Similarly, hexanal OAV was highest in the SBR of RD6 (121.55), followed by the SBR of KDML105 (90.21). Therefore, the SBR of RD6 had the highest rancid odor. Hexanal formation is greater in partially milled rice than in fully milled rice because partially milled contains rice germ and rice bran on its surface and similarly SBR rice contains more remnants of rice germ and rice bran than does LBR.

Heptanal is formed from oleic acid and has a fatty odor [6]. In the current study, heptanal was found in both LBR and SBR of all varieties. The LBR of CN1 had the highest heptanal content $(7.01 \mathrm{ng} / \mathrm{g}) \mathrm{and}$ the highest OAV (2.34). Heptanal was detected in all the broken rice samples, however heptanal's concentration and OAVs were lower than hexanal's in all varieties.

3-methylbutanal is derived from carbohydrates in rice [36]. In the current study, 3-methylbutanal was detected in the LBR of PTT1 and CN1 and in the SBR of KDML105, PTT1, and CN1. 3methylbutanal content was significantly higher $(p \leq 0.05)$ in all SBRs than in the corresponding LBRs. 
The SBR of CN1 had the highest 3-methylbutanal content $(17.52 \mathrm{ng} / \mathrm{g})$, followed by the SBR of KDML105 (14.14 ng/g). The SBR of CN1 also had the highest 3-methylbutanal OAV (50.05) of all varieties, followed by the SBR of KDML105 (40.41). 3-methylbutanal is a compound with an odor similar to malt [34,37]; however, in excessive amounts, it can cause a rancid odor or an off-flavor.

One should remember that the concentrations and OAVs of volatile compounds can vary from one test to another due to differences in the rice cultivar, growing location, growing conditions, milling conditions, and storage conditions.

Table $6 \mathrm{OAV}$ in broken rice.

\begin{tabular}{|c|c|c|c|c|c|c|c|c|c|c|c|c|}
\hline \multirow{3}{*}{ No. } & \multirow{3}{*}{ Compound $^{a}$} & \multirow{3}{*}{$\begin{array}{c}\mathbf{R I}^{c} \\
\text { BD5 }\end{array}$} & \multirow{3}{*}{$\begin{array}{c}\text { Odor } \\
\text { Threshold }^{d} \\
\text { (ng/g in water) }\end{array}$} & \multirow{3}{*}{ Odor quality } & \multicolumn{8}{|c|}{$\mathbf{O A V} \mathbf{V}^{f}$} \\
\hline & & & & & \multicolumn{4}{|c|}{ LBR } & \multicolumn{4}{|c|}{ SBR } \\
\hline & & & & & KDML105 & PTT1 & CN1 & RD6 & KDML105 & PTT1 & CN1 & RD6 \\
\hline 1 & 2-methyl-1-propanol & 646 & 1,000 & Solvent-like & ND & ND & ND & ND & ND & $<1$ & ND & ND \\
\hline 2 & 3-methylbutanal ${ }^{b}$ & 652 & 0.35 & Malty & ND & 17.35 & 32.83 & ND & 40.41 & 21.30 & 50.05 & ND \\
\hline 3 & Dimethyl disulfide & 735 & 12 & Cabbage-like & $<1$ & $<1$ & $<1$ & $<1$ & $<1$ & $<1$ & ND & $<1$ \\
\hline 4 & n-Hexanal ${ }^{b}$ & 798 & 4.5 & Tallowy, leaf-like & 18.23 & 15.77 & 31.27 & 77.30 & 90.21 & 41.93 & 39.15 & 121.55 \\
\hline 5 & 1-Hexanol & 867 & 2,500 & Green, flowery & ND & ND & $<1$ & ND & ND & ND & $<1$ & ND \\
\hline 6 & 2-Heptanone & 888 & 140 & Soapy, fruity & $<1$ & $<1$ & $<1$ & $<1$ & $<1$ & $<1$ & ND & $<1$ \\
\hline 7 & n-Heptanal ${ }^{b}$ & 902 & 3 & Fatty & $<1$ & $<1$ & 2.34 & 1.12 & 1.62 & 1.59 & $<1$ & 1.64 \\
\hline 8 & -(-)B-Pinene & 966 & $>2,000^{e}$ & Terpeny & $<1$ & ND & ND & ND & ND & ND & ND & ND \\
\hline 9 & 2-Pentylfuran ${ }^{b}$ & 984 & 6 & Green bean-like & $<1$ & $<1$ & $<1$ & 1.34 & $<1$ & $<1$ & $<1$ & 2.62 \\
\hline 10 & n-Octanal & 1002 & 0.7 & Fatty & $<1$ & ND & $<1$ & ND & ND & ND & $<1$ & ND \\
\hline 11 & S-(-)-(Limonene) & 1020 & $270^{e}$ & Citrus-like & $<1$ & $<1$ & $<1$ & $<1$ & $<1$ & $<1$ & $<1$ & $<1$ \\
\hline
\end{tabular}

${ }^{a}$ All compounds were confirmed by linear retention index, mass spectra comparison with NIST and Wiley databases.

${ }^{b}$ All compounds were confirmed by linear retention index, mass spectra comparison with NIST and Wiley data bases, and comparison with authentic standards.

${ }^{c}$ The Retention Index was calculated from GC-MS data using a DB5-MS column.

${ }^{d}$ odor threshold (ng/g in water)

${ }^{e}$ odor threshold (ng/g in air)

${ }^{f}$ The odor activity value was calculated by dividing the compound concentration by its odor detection threshold.

$\mathrm{ND}=$ not detected

\section{Conclusions}

This study investigated the grain quality, physicochemical and chemical properties, and volatile components of both the LBRs and SBRs of KDML105, PTT1, CN1 and RD6. The LBRs and SBRs of KDML105, PTT1 and RD6 had low gelatinization temperatures and short cooking times while CN1 had a medium gelatinization temperature and a longer cooking time. The LBR and SBR of RD6 both had a soft consistency and both were sticky. In contrast, the LBR and SBR of CN1 both had a hard consistency. The rheological properties of rice flour were found to correlate with the texture of cooked rice and varies depending on rice cultivars and amylose content which results in differences in gelatinization temperature, gel consistency, viscosity, retrogradation and cooking time. The protein content and lipid content in the SBR of all varieties was higher than in the corresponding LBR, except that the protein content in LBR and SBR of KDML105 was approximately equal, since both contain rice germ. LBR and SBR of CN1 had the highest amylose content, classifying CN1 as a firm cooked rice, while RD6 had the lowest amylose content, classifying RD6 as a soft and sticky cooked rice. The 6 most abundant volatile 
http://wjst.wu.ac.th

components detected were alcohols, aldehydes, furans, ketones, sulfur, and terpenes. The volatile compounds found to have highest odor active values in both the LBR and SBR of all varieties were hexanal, 3-methylbutanal, and heptanal, in that order.

\section{Acknowledgements}

This research was made possible with a generous grant from the Thailand Research Fund (TRF) of Research and Researchers for Industries (RRI).

\section{References}

[1] MC Custodio, RPa Cuevas, J Ynion, AG Laborte, ML Velasco and M Demont. Rice quality: How is it defined by consumers, industry, food scientists, andgeneticists? Trends Food Sci. Tech. 2019; 92, 122-37.

[2] JL Balindong, RM Ward, L Liu, TJ Rose, LA Pallas, BW Ovenden, PJ Snell and DLE Waters. Rice grain protein composition influences instrumental measures of rice cooking and eating quality. $J$. Cereal Sci. 2018; 79, 35-42.

[3] Z Zhou, K Robards, S Helliwell and C Blanchard. Composition and functional properties of rice. Int. J. Food Sci. Tech. 2002; 37, 849-68.

[4] X Wei, DD Handoko, L Pather, L Methven and JS Elmore. Evaluation of 2-acetyl-1-pyrroline in foods, with an emphasis on rice flavour. Food Chem. 2017; 232, 531-44.

[5] Y Biao, Z Chanjuan, Y Ming, H Dechun, DJ McClements, H Zhigang and C Chongjiang. Influence of gene regulation on rice quality: Impact of storage temperature and humidity on flavor profile. Food Chem. 2019; 283, 141-7.

[6] MA Monsoor and AProctor. Volatile component analysis of commercially milled head and broken rice. J. Food Sci. 2004; 69, C632-C636.

[7] P Dhankhar. Rice milling. J. Eng. 2014; 5, 34-42.

[8] H Xiao, T Yang, Q Lin, GQ Liu, L Zhang, F Yu and Y Chen. Acetylated starch nanocrystals: Preparation and antitumor drug delivery study. Int. J. Biol. Macromol. 2016; 89, 456-64.

[9] LR Chemutai, MA Musyoki, WF Kioko, NS Mwenda, KG Muriira and NM Piero. Physicochemical characterization of selected rice (Oryza sativa L.) genotypes based on gel consistency and alkali digestion. Biochem. Anal. Biochem. 2016; 5, 285.

[10] AOAC International. Official methods of analysis. Vol I. Association of Official Analytical Chemists. Washington DC, 1995.

[11] BO Juliano, CM Perez, AB Blakeney, DT Castillo, N Kongseree, B Laignelet, ET Lapis, VVS Murty, CM Paule and BD Webb. International cooperative testing on the amylose content of milled rice. Starch $1981 ; 33,157-62$.

[12] A Jarunruttanasri, C Theerakulkait and KR Cadwallader. Aroma components of acid-hydrolyzed vegetable protein made by partial hydrolysis of rice bran protein. J. Agric. Food Chem. 2007; 55, 3044-50.

[13] Thai Agricultural Standard. Thai Agricultural Standard TAS 4004-2012: Rice. Office of Thai Agricultural Standard and Food. Ministry of Agriculture and Cooperatives, Bangkok, Thailand, 2012.

[14] N Tangsrianugul, R Wongsagonsup and M Suphantharika. Physicochemical and rheological properties of flour and starch from Thai pigmented rice cultivars. Int. J. Biol. Macromol. 2019; 137, 666-75.

[15] KO Falade and AS Christopher. Physical, functional, pasting and thermal properties of flours and starches of six Nigerian rice cultivars. Food Hydrocoll. 2015; 44, 478-90.

[16] MJ Correa and C Ferrero. Thermal behaviour of wheat starch and flour at different water levels: Effect of pectins, modified celluloses and NaCl. Starch-Starke 2015; 67, 338-47. 
http://wjst.wu.ac.th

[17] H Zhong-Yang, L Jie, X Ke, D Qi-Gen, W Hai-Yan, G Jin-Long and Z Hong-Cheng. Effect of planting methods on quality of different growth and development types of Japonica rice under highyielding ultivation condition. Scientia Agricultura Sinica 2012; 45, 3932-45.

[18] B Jin-Long, X Fang-Fu, H Chao, Q Shi, G Jia-Lin, X Jing, Z Hong-Cheng and W Hai-Yan. Effects of planting methods on yield and quality of different types of japonica rice in northern Jiangsu plain, China. J. Integr. Agric. 2018; 17, 2624-35.

[19] A Haripriya, M Lidya, V Radhika and RMP Darshini. Quality characteristics of indigenous organic Indian rice variety: Kouni nel. Int. J. Home Sci. 2017; 3, 75-81.

[20] I Bjorck, AG Eliasson, A Drew, M Gudmundsson and R Karlsson. Some nutritional properties of starch and dietary fiber in barley genotypes containing different levels of amylose. Cereal Chem. 1990; 67, 327-33.

[21] BO Juliano and CP Vellareal. Grain quality evaluation of world rices. International Rice Research Institute, Manila, 1993, p. 8.

[22] CP Megha, D Ramesh and J Ramesh. Physico-chemical and cooking properties of selected rice varieties. Acta Sci. Nutr. Health 2019; 3, 23-30.

[23] JM Schiller, SA Lao, P Inthapanya and Hatsadong. Glutinous rice in Laos. In: Rice in Laos. International Rice Research Institute, Metro Manila, 2005, p. 197-214.

[24] Food Safety and Standards Authority of India. Manual of methods of analysis of foods. Government of India, New Delhi, 2015.

[25] M Harris. Confronting global climate change: Experiments \& applications in the tropics. CRC Press, Boca Raton, 2019, p. 32.

[26] A Thanonkaew, S Wongyai, JD McClements and AE Decker. Effect of stabilization of rice bran by domestic heating on mechanical extraction yield, quality, and antioxidant properties of cold-pressed rice bran oil (Oryza saltiva L.). Food Sci. Tech. 2012; 48, 231-6.

[27] WE Marshall and JI Wadsworth. Rice science and technology. CRC Press, New York, 1993, p. 41.

[28] P Koczon, E Gruczynska and B Kowalski. Changes in the acid value of butter during storage at different temperatures as assessed by standard methods or by FT-IR spectroscopy. Am. J. Food Tech. 2008; 3, 154-63.

[29] X Kong, P Zhu, Z Sui and J Bao. Physicochemical properties of starches from diverse rice cultivars varying in apparent amylose content and gelatinisation temperature combinations. Food Chem. $2015 ; 172,433-40$.

[30] L Amagliani, J O'Regan, AL Kelly and JA O'Mahony. The composition, extraction, functionality and applications of rice proteins: A review. Trends Food Sci. Tech. 2017; 64, 1-12.

[31] A Adams and N De Kimpe. Chemistry of 2-acetyl-1-pyrroline, 6-acetyl-1,2,3,4-tetrahydropyridine, 2-acetyl-2-thiazoline, and 5-acetyl-2,3-dihydro-4Hthiazine: Extraordinary Maillard flavor compounds. Chem. Rev. 2006; 106, 2299-319.

[32] R Widjaja, JD Craske and M Wootton. Changes in volatile components of paddy, brown and white fragrant rice during storage. J. Sci. Food Agric. 1996; 71, 218-24.

[33] JC Zhu, LY Wang, ZB Xiao and YW Niu. Characterization of the key aroma compounds in mulberry fruits by application of gas chromatography-olfactometry (GC-O), odor activity value (OAV), gas chromatography-mass spectrometry (GC-MS) and flame photometric detection (FPD). Food Chem. 2018; 245, 775-85.

[34] LG Dias, GHB Duarte, LRB Mariutti and N Bragagnolo. Aroma profile of rice varieties by a novel SPME method able to maximize 2-acetyl-1-pyrroline and minimize hexanal extraction. Food Res. Int. 2019; 123, 550-8.

[35] CJ Bergman, JT Delgado, R Bryant, C Grimm, KR Cadwallader and BD Webb. Rapid gas chromatographic technique for quantifying 2-acetyl-1-pyrroline and hexanal in rice (Oryza sativa L.). Cereal Chem. 2000; 77, 454-8.

[36] T Piyachaiseth, W Jirapakkul and S Chaiseri. Aroma compounds of flash-fried rice. Kasetsart J. (Nat. Sci.). 2011; 45, 717-29.

[37] MNNQ Izzreen, AS Hansen and MA Petersen. Volatile compounds in whole meal bread crust: The effects of yeast level and fermentation temperature. Food Chem. 2016; 210, 566-76. 